\title{
FOREWORD
}

\author{
ROBERT B. KAPLAN
}

\section{ARAL IX Rationale}

This ninth volume of the Annual Review of Applied Linguistics (ARAL) concerns itself with the issue of second language acquisition research (SLA). The goals of SLA are, primarily, to determine what is acquired and precisely how it is acquired, as Kachru points out below. These primary questions open a whole range of others. Obviously, language consists of a wide variety of features-phonological, morpho- logical, syntactic, discoursal, and so on-and it is important to understand whether there is an order in which these various features are acquired and, if they are acquired in packages, precisely what the interaction among the various features is in the process of acquisition. It is important to understand to what extent the acquisition of a second language is similar to or different from the acquisition of the first language or of any other language in a sequence. It is important to understand whether the linguistic distance between the first language and the target language creates any differential in the acquisition process or whether acquisition is a universal phenomenon operating without reference to the language(s) being acquired. It is important to understand whether, in the process of acquisition, learners acquire only the structures of the second language or whether they simultaneously acquire a set of cognitive structures peculiar to the target language and whether, if such a set of cognitive structures exists, it may, once acquired, operate together with the cognitive structures of the first language or whether these cognitive structures are language specific. It is important to know whether learners acquire the sociolinguistic rules of the target language along with the linguistic structures of the target language. It is important to understand whether these several acquisitional contexts occur without reference to the relative age of the learner or whether age is a factor affecting the rate of learning, the sequence of learning, and a range of other variables.

The current volume undertakes to examine some of these questions, raising both theoretical issues and issues relating to language pedagogy. The volume is organized into three parts. The first part considers specific linguistic features: phonology, morphology, syntax, semantics, vocabulary, and discourse features. The second part attempts to examine social and psychological factors, looking specifically at cognitive processes and strategies, at the role of input, at attitude and motivation, and at cognitive and cultural styles as they impact in second language 
acquisition. The third part examines the implications of these various concerns for classroom practices, specifically examining the effects of instruction, the use of various instructional models, and the important question of assessment; additionally, this section looks specifically at reading and writing. Because the subject is so complex and because research is really in its infancy (despite the fact that specifically identifiable SLA research has been going on for over a decade), it is not possible in this volume to provide a summary of all of the several issues. As the readings will show there is some disagreement among specialists in the field, and there is a complex terminological problem; it is clear that in this area, as in many others, the rapidity of research advances has led to a lack of standardization in terminology, and what appear to be similar phenomena are differently named by different researchers.

Hopefully, however, the articles in this volume will serve to place the various features of second language acquisition research into a broad perspective both with respect to the general fields of applied linguistics and with respect to the various sub-areas included in SLA, showing the origins of some of the questions and of some of the tentative answers to those questions. As several of the contributors to this volume suggest, the underlying paradigm for SLA research is by no means set. Perhaps this volume, by placing the various aspects of SLA in relation to each other, will contribute to the clearer definition of that paradigm. Indeed, this series of volumes has been constantly and regularly concerned with defining the scope of applied linguistics; it is clear that the activity surrounding second language acquisition research has played a significant role in defining some aspects of applied linguistics. This volume should be of some assistance to applied linguists in setting the parameters of second language acquisition research at least to the present time.

\section{PROCEDURAL NOTES}

In all sections, internal notes use parenthetical citation. All bibliographic entries follow the basic format of the Linguistic Society of America [LSA] , although a somewhat unique citation form is emerging for the $A R A L$ series. With respect to internal citation, the two types of bibliographies-annotated and unannotated - should be viewed as integrated, so that in instances where there is more than one entry for a given author for a particular year (e.g., 1980a; $1980 \mathrm{~b}$ ), it is possible that either of the entries may occur in either of the bibliographies; that is, 1980a may be in the annotated bibliography while 1980 b may be in the unannotated bibliography, or vice versa. No items are duplicated between the two separate bibliographic lists; that is, the item idenified as 1980a will not occur in both the annotated and the unannotated bibliography. Both types of bibliography-annotated and unannotated-are arranged in strict alphabetical order by the last name of the first author, that is, all the works authored by a particular individual will appear before all the works edited by the same author, and both of those entry types will precede works co-authored or co-edited by that same individual. Within each of these subcategories, items are arranged in chronological order, oldest item first, most recent item last. Multiple references to the same author (or set of authors) are indicated by the use of a solid line[___ $]$ of the same length as the name (or names) it replaces. Sources which include cited articles may not necessarily be represented in either bibliographic list if they are not in general germane to the particular area under discussion; in general, belletristic works cited as 
examples (or for more literary purposes) are not included in either bibliographic list, though they are identified in detail in the article in which they occur. In a few instances, where special bibliographic sets are included (e.g., legal citations), a separate list of the special references is included. In all texts contributed to the $A R A L$ series, an editorial effort has been made to conform generally to the usages and spellings common in the United States. Where possible, English translations of all non-English sources are provided. All contributed papers have been composed specifically for publication in the ARAL series and have not (unless otherwise specifically noted) appeared elsewhere previously, although their contents may have been used in whole or in part in oral presentations by the author(s).

The Editorial Directors do not assume reponsibility for the positions taken by contributors. Contributions often involve issues of policy as well as more clearly language-related issues. The Editorial Directors wish to be held blameless for opinions and errors of fact expressed by any contributor. The Editor-in-Chief apologizes in advance for any editorial errors which may have crept into the texts and accepts full responsibility for any such editorial errors, but not for substantive errors which are the sole responsibility of each contributor. Bibliographies are prepared and submitted by the contributors; the Editor-in-Chief makes every effort to assure the accuracy of each bibliographic entry that appears in every volume of $A R A L$, but in the case of materials not readily available in the United States, the Editor-in-Chief is dependent upon the accuracy of material submitted by the contributors. In some few instances, inclusive pages for cited articles which orginally appeared in anthologies or collections are not given; such omissions occur only when the original source is not available to the Editor-in-Chief and/or when the contributor has not supplied the appropriate pagination. In more recent volumes, every effort has been made, in connection with the citation of theses and dissertations, to provide a reference number for Dissertation Abstracts. In materials listed in well-known storage and retrieval networks like ERIC and the British Council's ELT Documents, reference numbers are also provided; when titles available only through electronic data bases are cited, every effort is made to provide an accession number (e.g., as in the ERIC files).

This ninth volume of $A R A L$ continues the practice, first established in the third volume, of including a running index of authors cited and topics covered in previous issues of $A R A L$. However, this list has become so large that it has become necessary to eliminate the listings from the earliest volumes. Thus, Volume VI (covering 1985) included a cumulative bibliography of Volumes I through V; beginning with Volume VII (covering 1986), as each new year is added, the oldest year's citations will be dropped from the list. In this issue (Volume IX, covering 1988), the cumulative citation listing will include citations from Volumes IV through VIII. Beginning with Volume V, a Contributor Index was added to the series; in each issue, all previous contributors to $A R A L$ are indexed in a single alphabetical list. There has not been a need to curtail this list; thus, it is complete for the entire series.

The indices are presented separately-an Author Index, a Subject Index, and a Contributor Index-at the end of each Volume. The Author Index cites every item that has appeared in the bibliographies accompanying each article. Each author citation is accompanied by one or more Roman numerals and Arabic numbers (e.g., Zeydel, E. II/160). The Roman numeral 
represents the number of the $A R A L$ Volume in which the author is cited, and the Arabic number represents the page(s) in that Volume on which the citation occurs. Thus, II/160 means that Zeydel is cited in ARAL II (the Volume published in 1982, covering the work of the year 1981). [Volume I, covering the research in the calendar year of 1980, was published (copyright date) in 1981; Volume II in 1982, etc.] Multiple sets of numbers (e.g., Valdman, A., aI/23, al/102, I/ 106) mean that the author is cited in more than one place. The prefixed lower case a (e.g., in al/ 23 ) indicates that the citation occurs in an annotated bibliography. Unmarked cases occur in unannotated bibliographies. U.S. government publications, court decisions, and public laws are listed separately at the end of the Author Index. To the extent that $A R A L$ may be said to represent the field accurately, the Author Index may become a citation index for use in merit and promotion evaluation in U. S. institutions.

The Subject Index provides the traditional alphabetical list of topics covered, giving inclusive pages by volume for the point at which the discussion occurs (e.g., II/106-123); this entry indicates that the subject is covered on pp. 106-123 in Volume II. Multiple number sets (e.g., Microsociolinguistics: $\mathrm{I} / 181-196, \mathrm{~V} / 47-48$ ) indicate that the subject (microsociolinguistics , in this case) is discussed in two places in the series, once in Volume I on pp. 181-196, and again in Volume $\mathrm{V}$ on pp. 47-48.

The Contributor Index provides a traditional alphabetical listing of all contributors to the $A R A L$ series since the beginning of the series. The citation includes the complete title of the contribution as well as the name of the contributor. Each entry, as in the other Indices, carries two designations (e.g., I/129); the first number designates the Volume in which the contribution occurs (in this case Volume II), and the second number indicates the page in that Volume on which the contribution begins.

It is the intent of the Editor-in-Chief to continue the several indices in future volumes of this series. It has been suggested that a complete bibliography of all works cited in $A R A L$ over the first ten years of its existence might constitute a useful contribution to the field; such a bibliography, published as a separate volume, would both offer a compendium of works considered important enough to cite by authors who are, presumably, experts in the various sub-fields of applied linguistics, and serve as the beginning of a citation index for the field. There are, obviously, a number of problems in compiling such a bibliography, since items listed as "in press" or "forthcoming" which have subsequently been published would need to be corrected, inclusive pages would need to be added, and items which have never appeared would have to be cited in a modified format. This is a massive undertaking. The Editorial Board seeks the views of scholars in the field. Comments would be welcome on the desirability of compiling such a bibliography. There has also been some discussion about the desirability of printing as an additional Index in $A R A L$ a list of all the journals which publish applied linguistic material. There is, within the organization TESOL, an Editorial Network, presently consisting of the editors of sixty-seven different journals published in the United States and some twelve other countries; it could be a service to the profession to have the names and editorial addresses of such a group of journals published in one convenient place. Again, the Editorial Board of $A R A L$ seeks the advice of its colleagues whether such a listing should be undertaken. In this instance, the project 
is not a complex one; it would only be a matter of receiving permission from the various editors to list their publications and editorial addresses.

\section{ACKNOWLEDGEMENTS}

The Editorial Directors and the Editor-in-Chief wish to acknowledge with deep gratitude and profound thanks the many hours invested by Audrey A. Kaplan in the preparation of the several indices, in the entering and proofreading of the final manuscript in camera-ready format, in the design and preparation of some of the graphics, and in the general logistic management of the entire enterprise. Without her efforts, neither this Volume nor the entire series to date would have been possible. We further wish to acknowledge the valuable editorial assistance of Dr. Sherrilynne Fuller. Finally, we acknowledge the support and assistance of the Cambridge University Press, and of the American Language Institute at the University of Southern California which has provided the Editor-in-Chief with the basic facilities and has absorbed some of the incidental costs associated with the production of this Volume. 